\title{
Normative Profile of the Efficacy and Way of Execution for the Block in Women's Volleyball from Under-14 to Elite Levels
}

\author{
Carlos Echeverría ${ }^{1}$, Enrique Ortega ${ }^{1}$, José Manuel Palao ${ }^{2}$
}

Affiliations: 'University of Murcia, Department of Physical Activity and Sports, Murcia, Spain, ${ }^{2}$ University of WisconsinParkside, Department of Health, Exercise Science and Sport Management, Kenosha, WI, United States

Correspondence: J.M. Palao, University of Wisconsin-Parkside, Department of Health, Exercise Science and Sport Management, SAC D140A, Kenosha, WI 53144, United States. E-mail: palaojm@gmail.com

ABSTRACT This study aimed to establish reference values for technical performance profile of the block regarding execution and efficacy according to the category of competition in female volleyball. The sample of the study was composed of a total of 9,024 blocks from 187 sets of 48 matches played by the top eight teams of under-14, under-16, under-18, 2nd national senior division, 1st national senior division, and international senior division. The design of the study was observational. The study's variables were the category of competition, game phase, block performance, block zone, number of player blocking, block intervention, and attack tempo. A descriptive and inferential analysis of official matches in all the levels of competition was carried out. The results show that at higher levels of competition, there was an increase in the number of errors, the number of direct points, and the number of contacts that limit the counterattack of the opponent. At higher levels, there is also higher participation of players in the block, mainly against 3rd tempo attacks. These values can help to monitor the evolution of female volleyball players and to establish training and competition goals.

KEY WORDS sport performance, team sport, match analysis, developmental stage

$@$ MJSSMontenegro

EFFICACY IN WOMEN'S VOLLEYBALL

http://mjssm.me/?sekcija=article\&artid=191

\section{Introduction}

In volleyball, the block is the first defensive action of a team to neutralize the opponent's attack (Selinger \& Ackermann-Blount, 1985). In high levels of competition, the block is the second action in importance related to success in a match (Castro, Souza, \& Mesquita, 2011; Eom \& Schutz, 1992; Marcelino \& Mesquita, 2006; Palao, Santos, \& Ureña, 2004a; Peña, Rodríguez-Guerra, Buscá, \& Serra, 2013; Rodriguez-Ruiz et al., 2011). When players do a block, they have a disadvantage compared to spikers, due to biomechanical and tactical aspects (Afonso \& Mesquita, 2011; Vint, 1998). For that reason, block efficacy is also measured in the restrictions that it imposed to the opposite team in the type and direction of hitting (Palao et al., 2004b; Selinger \& Ackermann-Blount, 1985). An effective block depends on the anthropometrics of players, their physical condition, blocking technique, strategy, experience, and decision making (Amasay, 2008; Araujo, Afonso, \& Mesquita, 2011; Malá, Malý, Záhalka, \& Bunc, 2010). These aspects may be improved through the different stages of development of players due to maturation, training, and experience. Therefore, it is possible that block efficacy and way of execution change through these stages. The absence of this information could affect the way of the development of the block action by players in different age groups and levels of competition.

The block is one of the most difficult skills to master (García-Alcaraz, Ortega, \& Palao, 2016; Palao et al., 2004b). Specifically, the variables that affect the success in the block are (Silva, Lacerda, \& João, 2014): a) timing with a defensive line; b) speed in passing of opposite setter; c) variety of attacking options in the opposite team; and d) direction of the ball's trajectory. The higher the level of competition, the quicker and more unpredictable the opposite's attack becomes (Katsikadelli, 1995; Marcelino, Afonso, Moraes, \& Mesquita, 2014; Palao et al., 2005). This gives the attack an advantage over the block (Inkinen, Häyrinen, \& Linnamo, 2013). 
Despite the imbalance between attack and block, the block is still a critical element in a game. For instance, in male volleyball, the block is a skill that differentiates teams of similar level in senior high competition (Kapidzic, Ahmic, \& Selimovic, 2013; Palao et al., 2004a; Rodriguez-Ruiz et al., 2010). In female volleyball, the block is not as relevant as it is in male volleyball, due to the players' lower jump heights and movement capacities (Bergeles, Barzouka, \& Nikolaidou, 2009), but some differences arise in the way of playing. These differences make a slightly higher occurrence of collective block in female volleyball than in male volleyball (Palao et al., 2004a).

The information found about the block action is related to higher levels of competition, not to formative groups. The information available does not provide objective reference values to evaluate players' progression through their athletic development. This information could enhance the knowledge of how the training process takes effect and provides guidelines of training to coaches. Also, this data can provide specific technical-tactical reference values to evaluate the block actions in different age groups and levels of competition. The study aimed to establish reference values for the technical performance profile of the block regarding execution and efficacy according to the category of competition in female volleyball.

TABLE 1. Distribution of the sample for the different age groups and levels of competition (women's volleyball)

\begin{tabular}{cccccccc} 
Sample & \multicolumn{8}{c}{ Levels } & Total \\
\cline { 2 - 7 } & $\mathbf{U - 1 4}$ & $\mathbf{U}-\mathbf{1 6}$ & $\mathbf{U}-\mathbf{1 8}$ & $\mathbf{2}^{\text {nd }}$ national & $\mathbf{1}^{\text {st }}$ national & International & \\
\hline Matches & 8 & 8 & 8 & 8 & 8 & 8 & 48 \\
Sets & 29 & 35 & 32 & 27 & 31 & 33 & 187 \\
Sequences & 1,216 & 1,402 & 1,406 & 1,798 & 1,753 & 1,449 & 9,024 \\
\hline
\end{tabular}

\section{Methods}

The sample was 9,024 sequences from 187 sets of 48 volleyball matches (eight matches of each category of competition studied: Spanish national U-14 championship, Spanish national U-16 championship, Spanish national U-18 championship, Spanish senior 2nd national division, Spanish senior 1st national division, and senior international level). The sample was intentional and included matches between the top eight teams in the 2006 Spanish National Championship and the 2006 World Championship, respectively. The matches selected were the quarterfinals, semifinals, and finals. Table 1 shows the distribution of the sample by categories. The ethics commission of the principal researcher pre-approved the study project, in compliance with the principles of the Helsinki Declaration.

TABLE 2. Performance of the block according to game phase and levels of competition (women's volleyball)

\begin{tabular}{|c|c|c|c|c|c|c|c|c|c|c|c|c|}
\hline \multirow{2}{*}{ Performance } & \multicolumn{2}{|c|}{ U-14 } & \multicolumn{2}{|c|}{ U-16 } & \multicolumn{2}{|c|}{ U-18 } & \multicolumn{2}{|c|}{$2^{\text {nd }}$ national } & \multicolumn{2}{|c|}{$1^{\text {st }}$ national } & \multicolumn{2}{|c|}{ International } \\
\hline & $\mathbf{n}$ & $\%$ & $\mathbf{n}$ & $\%$ & $\mathbf{n}$ & $\%$ & $\mathbf{n}$ & $\%$ & $\mathbf{n}$ & $\%$ & $\mathbf{n}$ & $\%$ \\
\hline \multicolumn{13}{|c|}{ Serve and side-out defense } \\
\hline Error & $30^{-}$ & 5.8 & $43^{-}$ & 6.8 & $61^{-}$ & 9.3 & 107 & 11.8 & $149^{+}$ & 15.5 & $143^{+}$ & 16.9 \\
\hline Allow all attacks & $426^{+}$ & 83.0 & $464^{+}$ & 73.3 & 446 & 67.7 & 558 & 61.5 & $555^{-}$ & 57.8 & $499^{-}$ & 58.8 \\
\hline Limited attacks & 19 & 3.7 & 69 & 10.9 & 88 & 13.4 & $153^{+}$ & 16.9 & 146 & 15.2 & 123 & 14.5 \\
\hline No attack & 12 & 2.3 & 15 & 2.4 & 25 & 3.8 & 28 & 3.1 & 31 & 3.2 & 24 & 2.8 \\
\hline Point & 26 & 5.1 & 42 & 6.6 & 39 & 5.9 & 61 & 6.7 & 80 & 8.3 & 59 & 7.0 \\
\hline Coefficient & \multicolumn{2}{|c|}{1.18} & \multicolumn{2}{|c|}{1.29} & \multicolumn{2}{|c|}{1.29} & \multicolumn{2}{|c|}{1.31} & \multicolumn{2}{|c|}{1.31} & \multicolumn{2}{|c|}{1.24} \\
\hline \multicolumn{13}{|c|}{ Counter-attack defense } \\
\hline Error & 39 & 5.5 & $49^{-}$ & 6.4 & 68 & 9.1 & 101 & 11.3 & 77 & 9.7 & $94^{+}$ & 15.6 \\
\hline Allow all attacks & $577^{+}$ & 82.1 & $597^{+}$ & 77.6 & 517 & 69.2 & 580 & 65.1 & 524 & 66.2 & $333^{-}$ & 55.4 \\
\hline Limited attacks & 45 & 6.4 & 76 & 9.9 & 101 & 13.5 & 135 & 15.2 & 117 & 14.8 & $110^{+}$ & 18.3 \\
\hline No attack & 13 & 1.8 & 18 & 2.3 & 21 & 2.8 & 23 & 2.6 & 26 & 3.3 & 16 & 2.7 \\
\hline Point & 29 & 4.1 & $29^{-}$ & 3.8 & 40 & 5.4 & 52 & 5.8 & 48 & 6.1 & $48^{+}$ & 8.0 \\
\hline Coefficient & \multicolumn{2}{|c|}{1.17} & \multicolumn{2}{|c|}{1.20} & \multicolumn{2}{|c|}{1.26} & \multicolumn{2}{|c|}{1.26} & \multicolumn{2}{|c|}{1.30} & \multicolumn{2}{|c|}{1.32} \\
\hline \multicolumn{13}{|c|}{ Total } \\
\hline Error & $69-$ & 5.7 & $92^{-}$ & 6.6 & 129 & 9.2 & 208 & 11.6 & $226^{+}$ & 12.9 & $237^{+}$ & 16.4 \\
\hline Allow all attacks & $1003^{+}$ & 82.5 & $1061^{+}$ & 75.7 & 963 & 68.5 & 1138 & 63.3 & 1079 & 61.6 & 832 & 57.4 \\
\hline Limited attacks & 64 & 5.3 & $145^{\circ}$ & 10.3 & 189 & 13.4 & $288^{+}$ & 16.0 & $263^{+}$ & 15.0 & $233^{+}$ & 16.1 \\
\hline No attack & 25 & 2.1 & 33 & 2.4 & 46 & 3.3 & 51 & 2.8 & 57 & 3.3 & 40 & 2.8 \\
\hline Point & $55^{-}$ & 4.5 & 71 & 5.1 & 79 & 5.6 & 113 & 6.3 & $128^{+}$ & 7.3 & $107^{+}$ & 7.4 \\
\hline Coefficient & \multicolumn{2}{|c|}{1.00} & \multicolumn{2}{|c|}{1.23} & \multicolumn{2}{|c|}{1.19} & \multicolumn{2}{|c|}{1.22} & \multicolumn{2}{|c|}{1.23} & \multicolumn{2}{|c|}{1.19} \\
\hline
\end{tabular}

Note: $\mathrm{o}^{+}$statistical signification of $\mathrm{p}<0.05$ (chi square test). ${ }^{+} \mathrm{o}^{-}$relationship found (positive or negative). 
TABLE 3. Efficiency of blocking according to game phase, timing of the attack and levels of competition (women's volleyball)

\begin{tabular}{|c|c|c|c|c|c|c|c|c|c|c|c|c|}
\hline \multirow{2}{*}{ Timing attack } & \multicolumn{2}{|c|}{ U-14 } & \multicolumn{2}{|c|}{ U-16 } & \multicolumn{2}{|c|}{ U-18 } & \multicolumn{2}{|c|}{$2^{\text {nd }}$ national } & \multicolumn{2}{|c|}{$1^{\text {st }}$ national } & \multicolumn{2}{|c|}{ International } \\
\hline & $\mathbf{n}$ & Coef & $\mathbf{N}$ & Coef & $\mathbf{n}$ & Coef & $\mathbf{n}$ & Coef & $\mathbf{n}$ & Coef & $\mathbf{n}$ & Coef \\
\hline \multicolumn{13}{|c|}{ Serve and side-out defense } \\
\hline $1^{\circ}$ Tempo & - & - & - & - & 19 & 1.12 & 84 & 1.32 & 133 & 1.23 & 126 & 1.31 \\
\hline $2^{\circ}$ Tempo & - & - & 3 & 1 & 48 & 1.23 & 122 & 1.37 & 107 & 1.30 & 146 & 1.15 \\
\hline 3० Tempo & 492 & $1.14^{\text {cde }}$ & 611 & 1.27 & 584 & $1.37^{\mathrm{a}}$ & 685 & $1.30^{\mathrm{a}}$ & 701 & $1.34^{\mathrm{a}}$ & 565 & 1.19 \\
\hline At $2^{\text {nd }}$ touch & 29 & 1.74 & 18 & 1.68 & 9 & 1.56 & 16 & 0.83 & 25 & 1.55 & 15 & 1.42 \\
\hline At $1^{\text {st }}$ touch & - & - & 1 & 0 & - & - & 1 & 1 & 1 & 2 & 2 & 1 \\
\hline \multicolumn{13}{|c|}{ Counter-attack defense } \\
\hline $1^{\circ}$ Tempo & - & - & 1 & 1 & 16 & 1.07 & 42 & 1.22 & 45 & 1.14 & 37 & 1.18 \\
\hline $2^{\circ}$ Tempo & 10 & 1.15 & 21 & 1.39 & 46 & 1.34 & 45 & 1.42 & 46 & 1.43 & 22 & 1.08 \\
\hline $3^{\circ}$ Tempo & 578 & $1.09^{\text {def }}$ & 653 & $1.16^{\mathrm{e}}$ & 612 & 1.18 & 694 & $1.29^{\mathrm{a}}$ & 559 & $1.28^{\mathrm{ab}}$ & 456 & $1.38^{\mathrm{a}}$ \\
\hline At $2^{\text {nd }}$ touch & 47 & 1.62 & 42 & 1.39 & 21 & 1.75 & 33 & 1.36 & 40 & 1.70 & 21 & 1.43 \\
\hline At $1^{\text {st }}$ touch & 29 & 1.12 & 28 & $1.25^{c}$ & 22 & $0.64^{\text {bef }}$ & 52 & 1.26 & 57 & $1.21^{\mathrm{c}}$ & 34 & $0.95^{c}$ \\
\hline \multicolumn{13}{|c|}{ Total } \\
\hline $1^{\circ}$ Tempo & - & - & 1 & 1 & 35 & 1.09 & 126 & 1.25 & 178 & 1.17 & 163 & 1.23 \\
\hline $2^{\circ}$ Tempo & 10 & 1.15 & 24 & 1.34 & 94 & 1.31 & 167 & 1.40 & 153 & 1.38 & 168 & 1.11 \\
\hline $3^{\circ}$ Tempo & 1070 & $1.11^{\text {bcdef }}$ & 1264 & $1.20^{\mathrm{ae}}$ & 1196 & $1.25^{\mathrm{a}}$ & 1379 & $1.29^{\mathrm{a}}$ & 1260 & $1.30^{\mathrm{ab}}$ & 1021 & $1.31^{\mathrm{a}}$ \\
\hline At $2^{\text {nd }}$ touch & 76 & 1.66 & 60 & 1.48 & 30 & 1.68 & 49 & 1.72 & 65 & 1.65 & 36 & 1.43 \\
\hline At $1^{\text {st }}$ touch & 29 & 1.12 & 29 & 1.11 & 22 & $0.64^{\mathrm{de}}$ & 53 & $1.24^{\mathrm{c}}$ & 58 & $1.28^{c}$ & 36 & 0.96 \\
\hline
\end{tabular}

Note: ${ }^{a} p<0.05$ in U-14. ${ }^{b} p<0.05$ in U-16. ${ }^{c} p<0.05$ in U-18. ${ }^{d} p<0.05$ in 2 nd national division. ${ }^{e} p<0.05$ in 1 st national division. ${ }^{f} p<0.05$ in international. ${ }^{\circ}{ }^{+}$statistical signification of $\mathrm{p}<0.05$ (chi square test). ${ }^{+} \mathrm{o}^{-}$relationship found (positive or negative).

The design of the study was descriptive punctual, nomothetic, multidimensional, inter-, and intra-group correlational (Anguera, Blanco, \& Losada, 2001). The variables of the study were: "age group and level of competition" (national U-14, national U-16, national U-18, 2nd national senior division, 1st national senior division, and international senior level), game phase (side-out defence, and counter-attack defence), block performance (on a scale from 0 to 4 ), block zone (net was divided into three equal zones), number of players blocking (one, two or three), block intervention (no touch, block-out, ball returned to the attacker court, and ball contact and not returned), and attack tempo (first-tempo, second-tempo, third-tempo, second contact attack, and attacks at the first contact of the sequence of the game). For the categories of block performance, an efficacy coefficient (sum of attempts per category multiplied by the value of the level and divided by total attempts (0-4)), a pointto-error ratio, and an efficiency value (points or perfect actions minus errors) were calculated.

All recordings were made at public sport events without any influence in the game. All of them were official matches, and they were recorded with a video camera in live performance. The variables registered are part of the observation instrument (Observation Instrument of Techniques and Efficacy in Volleyball) that was designed and validated by Palao and Manzanares (2009) and Palao, Manzanares, and Ortega (2015). The observation was done by a single observer, who held a sports science degree, had the highest coaching certification in Spain, and had more than five years of experience as a coach and volleyball analyst. The observer was trained with the observation instrument before beginning the study (Palao \& Manzanares, 2009). After the training period, inter- and intra-observer reliability were calculated (Cronbach's Alpha). To calculate the inter-observer reliability, another researcher was used as a reference. This researcher also held a sports science degree, had the highest coaching certification in Spain, and had more than ten years of experience. A lowest inter-observer reliability of 0.82 and a lowest intra-observer reliability of 0.96 (Kappa-Cohen test) were calculated.

A descriptive analysis (occurrence, occurrence percentage, means, standard deviation, and coefficient of performance values) and an inferential analysis were made. The Kolmogorov-Smirnov test was used to analyse the normality of the sample. Due to the normal distribution of all variables, the Chi-square test was used to study the differences in each category, and the Mann-Whitney $U$ was used to analyse the differences between categories. The analyses were done with SPSS 21 software. The level of significance was established at $\mathrm{p}<.05$.

Results

In general, the errors, direct points, and blocks that limited the opposite's counterattack were significantly lower in early stages and significantly higher in the 1st national senior division and senior international levels. The blocks that allowed all counterattack options to the opponent team had a significantly higher occurrence in under-14 and under-16 and significantly lower occurrence in all senior categories. Regarding the game phase (Table 2), in the serve-defence phase, the errors had significantly lower occurrence in the early stages of training than in senior categories. The blocks that limit the opponent counterattack had a significantly higher occurrence in under-14 and under-16 and significantly lower in the 1st national senior 
division and senior international levels. In the counter-attack defence phase, the errors and the blocks that limited the opponents' counter-attack options had a lower occurrence in under-14 and under-16 and significantly higher occurrence at the international level. The blocks that limited the opponent's counterattack had a significantly higher occurrence in under-14 and under-16 and significantly lower occurrence in the senior international level.

TABLE 4. Destination of the block according to game phase, timing of the attack and levels of competition (women's volleyball)

\begin{tabular}{|c|c|c|c|c|c|c|c|c|c|c|c|c|}
\hline \multirow{2}{*}{ Participation } & \multicolumn{2}{|c|}{ U-14 } & \multicolumn{2}{|c|}{ U-16 } & \multicolumn{2}{|c|}{ U-18 } & \multicolumn{2}{|c|}{$2^{\text {nd }}$ national } & \multicolumn{2}{|c|}{$1^{\text {st }}$ national } & \multicolumn{2}{|c|}{ International } \\
\hline & $\mathbf{N}$ & $\%$ & $\mathbf{n}$ & $\%$ & $\mathbf{n}$ & $\%$ & $\mathbf{n}$ & $\%$ & $\mathbf{n}$ & $\%$ & $\mathbf{n}$ & $\%$ \\
\hline \multicolumn{13}{|c|}{ Serve and side-out defense } \\
\hline No touch & $429^{+}$ & 82.5 & $427^{+}$ & 67.5 & 400 & 60.7 & 516 & 56.8 & $536^{-}$ & 55.4 & $477^{-}$ & 55.9 \\
\hline Block-out & 6 & 1.2 & $20^{-}$ & 3.2 & 40 & 6.1 & 54 & 5.9 & $82^{+}$ & 8.5 & $81^{+}$ & 9.5 \\
\hline Ball returned & $41^{-}$ & 7.9 & 114 & 18.0 & 129 & 19.6 & 170 & 18.7 & 185 & 19.1 & 175 & 20.5 \\
\hline Ball not returned & 44 & 8.5 & $72^{-}$ & 11.4 & 90 & 13.7 & $168^{+}$ & 18.5 & $164^{+}$ & 17.0 & 121 & 14.2 \\
\hline \multicolumn{13}{|c|}{ Counter-attack defense } \\
\hline No touch & $538^{+}$ & 75.9 & $565^{+}$ & 72.3 & 478 & 63.3 & $532^{-}$ & 58.3 & 489 & 59.9 & $326^{-}$ & 52.6 \\
\hline Block-out & 14 & 2.0 & $29^{-}$ & 3.7 & 38 & 5.0 & 67 & 7.3 & 64 & 7.8 & $73^{+}$ & 11.8 \\
\hline Ball returned & $97^{-}$ & 13.7 & 118 & 15.1 & 143 & 18.9 & 173 & 19.0 & 137 & 16.8 & 118 & 19.0 \\
\hline Ball not returned & $59^{-}$ & 8.3 & $69^{-}$ & 8.8 & 95 & 12.6 & $140^{+}$ & 15.4 & $127^{+}$ & 15.5 & $103^{+}$ & 16.6 \\
\hline \multicolumn{13}{|c|}{ Total } \\
\hline No touch & $967^{+}$ & 78.7 & $992^{+}$ & 70.2 & 878 & 62.1 & $1048^{-}$ & 57.6 & 1025 & 57.5 & $803^{-}$ & 54.5 \\
\hline Block-out & 20 & 1.6 & $49^{-}$ & 3.5 & 78 & 5.5 & 121 & 6.6 & $146^{+}$ & 8.2 & $154^{+}$ & 10.4 \\
\hline Ball returned & $138^{-}$ & 11.2 & 232 & 16.4 & 272 & 19.2 & 343 & 18.8 & 322 & 18.0 & $293^{+}$ & 19.9 \\
\hline Ball not returned & $103^{-}$ & 8.4 & $141^{-}$ & 10.0 & 185 & 13.1 & $308^{+}$ & 16.9 & $291^{+}$ & 16.3 & 224 & 15.2 \\
\hline
\end{tabular}

Note: $\mathrm{o}^{+}$statistical signification of $\mathrm{p}<0.05$ (chi square test). ${ }^{+} \mathrm{o}-$ relationship found (positive or negative).

According to the attack tempo (Table 3), the efficacy of blocks against the 3rd tempo attack had significantly lower occurrence in under-14 and significantly higher occurrence in all senior categories in the side-out defence and counter-attack defence phases.

Regarding the participation of the block (Table 4), the blocks that did not contact the ball in the serve-defence phase and counter-attack defence phase were significantly higher in under-14 and under-16, and significantly lower in the 2 nd and the 1 st national senior divisions and senior international levels. The occurrence of block-out had a significantly higher occurrence in the 1st national division and international level and lower in under-14 and under-16. The occurrences of the blocks that touched the ball and the ball that passed behind the block were significantly lower in under-14 and significantly higher in the senior international level. The occurrence of the blocks that touched the ball and returned to the opposite field had a significantly lower occurrence in under-14 and under-16 and significantly higher in the 2nd and 1st national senior divisions.

TABLE 5. Efficiency of the block according to game phase, zone and levels of competition (women's volleyball)

\begin{tabular}{|c|c|c|c|c|c|c|c|c|c|c|c|c|}
\hline \multirow{2}{*}{$\begin{array}{l}\text { Zone of } \\
\text { blocking }\end{array}$} & \multicolumn{2}{|c|}{ U-14 } & \multicolumn{2}{|c|}{ U-16 } & \multicolumn{2}{|c|}{ U-18 } & \multicolumn{2}{|c|}{$2^{\text {nd }}$ national } & \multicolumn{2}{|c|}{$1^{\text {st }}$ national } & \multicolumn{2}{|c|}{ International } \\
\hline & $\mathbf{n}$ & Coef & $\mathbf{n}$ & Coef & $\mathbf{n}$ & Coef & $\mathbf{n}$ & Coef & $\mathbf{n}$ & Coef & $\mathbf{n}$ & Coef \\
\hline \multicolumn{13}{|c|}{ Serve and side-out defense } \\
\hline Zone 4 & $163^{+}$ & 1.18 & 158 & 1.20 & 168 & 1.41 & 281 & 1.28 & 322 & 1.31 & 310 & 1.24 \\
\hline Zone 3 & 134 & 1.22 & $179^{-}$ & 1.23 & 141 & 1.29 & $218^{+}$ & 1.37 & $203^{+}$ & 1.23 & $182^{+}$ & 1.20 \\
\hline Zone 2 & 221 & $1.13^{\text {bcde }}$ & 292 & $1.33^{\mathrm{a}}$ & 349 & $1.35^{\mathrm{a}}$ & 407 & $1.28^{\mathrm{a}}$ & 424 & $1.42^{\mathrm{a}}$ & 355 & 1.21 \\
\hline \multicolumn{13}{|c|}{ Counter-attack defense } \\
\hline Zone 4 & $75^{-}$ & $1.12^{\mathrm{e}}$ & 111 & $1.11^{\mathrm{de}}$ & 162 & 1.13 & 265 & $1.24^{\mathrm{b}}$ & 237 & $1.48^{\mathrm{ab}}$ & 187 & 1.24 \\
\hline Zone 3 & $368^{+}$ & $1.13^{\mathrm{e}}$ & $313^{+}$ & 1.22 & 170 & 1.08 & $200^{-}$ & 1.19 & $143^{-}$ & $1.32^{\mathrm{a}}$ & $100^{-}$ & 1.04 \\
\hline Zone 2 & 266 & 1.24 & 358 & $1.2^{c}$ & 425 & $1.62^{\mathrm{b}}$ & 435 & 1.33 & 405 & 1.35 & 323 & 1.50 \\
\hline \multicolumn{13}{|c|}{ Total } \\
\hline Zone 4 & $238^{-}$ & $1.15^{\mathrm{e}}$ & $269^{-}$ & $1.15^{\mathrm{e}}$ & $330^{-}$ & 1.27 & $546^{+}$ & 1.26 & $559^{+}$ & $1.39^{\mathrm{ab}}$ & $497^{+}$ & 1.24 \\
\hline Zone 3 & $502^{+}$ & 1.18 & $492^{+}$ & 1.23 & $311^{-}$ & 1.74 & $418^{-}$ & 1.28 & $346^{-}$ & 1.27 & $282^{-}$ & 1.12 \\
\hline Zone 2 & $487^{-}$ & 1.19 & $650^{-}$ & 1.26 & 774 & 1.49 & $842^{+}$ & 1.30 & $829^{+}$ & 1.39 & $678^{+}$ & 1.35 \\
\hline
\end{tabular}

Note: ${ }^{a} p<0.05$ in U-14. ${ }^{b} p<0.05$ in U-16. ${ }^{c} p<0.05$ in U-18. ${ }^{d} p<0.05$ in 2 nd national division. ${ }^{e} p<0.05$ in 1 st national division. ${ }^{f} p<0.05$ in international. ${ }^{-}{ }^{+}$statistical signification of $\mathrm{p}<0.05$ (chi square test). ${ }^{+} \mathrm{o}^{-}$relationship found (positive or negative). 
TABLE 6. Efficiency of the block according to the number of hands blocking and levels of competition (women's volleyball)

\begin{tabular}{|c|c|c|c|c|c|c|c|c|c|c|c|c|}
\hline \multirow{2}{*}{ Action } & \multicolumn{2}{|c|}{ U-14 } & \multicolumn{2}{|c|}{ U-16 } & \multicolumn{2}{|c|}{ U-18 } & \multicolumn{2}{|c|}{$2^{\text {nd }}$ national } & \multicolumn{2}{|c|}{$1^{\text {st }}$ national } & \multicolumn{2}{|c|}{ International } \\
\hline & $\mathbf{n}$ & $\%$ & $\mathbf{n}$ & $\%$ & $\mathbf{n}$ & $\%$ & $\mathbf{n}$ & $\%$ & $\mathbf{n}$ & $\%$ & $\mathbf{n}$ & $\%$ \\
\hline \multicolumn{13}{|c|}{ One blocker } \\
\hline No touch & $620^{+}$ & 29.5 & 407 & 19.4 & 282 & 13.4 & 314 & 15.0 & 283 & 13.5 & 194 & 9.2 \\
\hline BlockOut & 7 & 8.9 & 6 & 7.6 & 10 & 12.7 & 14 & 17.7 & 18 & 22.8 & $24^{+}$ & 30.4 \\
\hline Ball returned & $77^{-}$ & 21.2 & 62 & 17.1 & 45 & 12.4 & 61 & 16.8 & 66 & 18.2 & $52^{+}$ & 14.3 \\
\hline Ball not returned & 64 & $21.2^{\text {def }}$ & 32 & 10.6 & 38 & 12.6 & $72^{+}$ & $23.8^{\mathrm{a}}$ & 55 & $18.2^{\mathrm{a}}$ & 41 & $13.6^{\mathrm{a}}$ \\
\hline \multicolumn{13}{|c|}{ Two blockers } \\
\hline No touch & $302^{+}$ & 9.1 & $547^{+}$ & 16.5 & 559 & 16.8 & 689 & 20.7 & 678 & 20.4 & 548 & 16.5 \\
\hline BlockOut & 9 & 2.2 & 32 & 7.8 & 60 & 14.6 & 91 & 22.1 & 101 & 24.5 & $119^{+}$ & 28.9 \\
\hline Ball returned & $60^{\circ}$ & $5.1^{\text {bcdef }}$ & 166 & $14.1^{\mathrm{a}}$ & 215 & $18.3^{\mathrm{a}}$ & 273 & $23.2^{\mathrm{a}}$ & 240 & $20.4^{a}$ & 221 & $18.8^{\mathrm{a}}$ \\
\hline Ball not returned & $29^{-}$ & 3.3 & $105^{-}$ & $11.9^{\text {cde }}$ & 138 & $15.7^{b}$ & $225^{+}$ & $25.6^{\text {bef }}$ & $217^{+}$ & $24.7^{b d}$ & 166 & $18.9^{d}$ \\
\hline \multicolumn{13}{|c|}{ Three blockers } \\
\hline No touch & 3 & 4.5 & 11 & 16.4 & 7 & 10.4 & 7 & 10.4 & 21 & 31.3 & 18 & 26.9 \\
\hline BlockOut & - & - & - & - & 1 & 16.7 & - & - & 3 & 50.0 & 2 & 33.3 \\
\hline Ball returned & - & - & 4 & 8.9 & 11 & 24.4 & 9 & 20.0 & 9 & 20.0 & 12 & 26.7 \\
\hline Ball not returned & 1 & 4.8 & - & - & 2 & 9.5 & 4 & 19.0 & 7 & 33.3 & 7 & 33.3 \\
\hline
\end{tabular}

Note: ${ }^{a} p<0.05$ in U-14. ${ }^{b} p<0.05$ in U-16. ${ }^{c} p<0.05$ in U-18. ${ }^{d} p<0.05$ in 2 nd national division. ${ }^{e} p<0.05$ in 1 st national division. ${ }^{f} p<0.05$ in international. ${ }^{-0}{ }^{+}$ statistical signification of $\mathrm{p}<0.05$ (chi square test). ${ }^{+} \mathrm{o}^{-}$relationship found (positive or negative).

According to the zone of execution (Table 5), in the side-out defence, the occurrence of blocks in zone 3 was significantly higher in the senior levels and significantly lower in under-14 and under-16. In the counter-attack defence phase, the occurrence of blocks in zone 3 was significantly higher in under-14 and under-16 and significantly lower in senior categories. In zone 3 , there was a significantly higher number of blocks in under-14 and under-16 than in senior categories. In zone 4, the occurrence of blocks was significantly lower in under-14, under 16 and under-18 than in the 2nd and 1st national senior divisions and the senior international level. The efficacy of the block in zone 2 was significantly lower in under-14 in the side out defence phase than in the rest of the categories studied.

Regarding the number of blockers (Table 6), the occurrence of the block by one player and two players without touching the ball was significantly higher in under-14 and significantly lower in the senior international level. The occurrence of block-out by one player and two players was significantly lower in under-14 and under-16 and significantly higher in the senior international level. The occurrence of block by one player that returned the ball to the opponent court was significantly lower in under-14 and significantly higher in the senior international level. The occurrence of blocks by two players and the ball passing behind the block was significantly lower in under-14 and under-16 and significantly higher in 2 nd and 1 st national senior divisions. Senior levels had an efficacy significantly lower in the one-player-block that touched the ball and passed behind the block. The efficacy of two players-block that touched the ball and returned to the opponent court was significantly lower in under-14 than the rest of categories studied.

Discussion

This study provides reference values of the performance and a way of execution of the block in female volleyball players from under-14 to senior international categories. The results showed that the higher the category of competition, the higher the involvement of the block in the game. However, the higher participation does not involve a higher efficiency, due to the increase of the block errors and the block that limits the attack options. The block is the most difficult technical action to make (McGown, Fronske, \& Moser, 2001; Palao et al., 2004b; Selinger \& Ackermann-Blount, 1985). Its difficulty comes from the imbalance with the attack (Afonso \& Mesquita, 2011; Marcelino et al., 2014; Silva et al., 2014), due to the types of opposite's setting, attack's tactics, ball's trajectory. All of these put the blockers at a disadvantage compared to the opposite's spikers (Inkinen et al., 2013; Marcelino \& Mesquita, 2006; Palao et al., 2004b). As the level becomes higher, it becomes more difficult to block quicker and unpredictable opposite attacks (Katsikadelli, 1995; Marcelino et al., 2014; Palao et al., 2005). The highest demands in competition necessitate specific training and an appropriate physical condition (Malá et al., 2010; McGown et al., 2001). These improvements could increase the participation in the game (e.g., block that contacts the ball) with similar levels of block performance (Eom \& Schutz, 1992a; Palao et al., 2004a; Peña et al., 2013; Rodríguez-Ruiz et al., 2011).

The efficiency of the block shows differences according to the game phase. In the side-out defence phase, there were no differences between the categories of competition. In the counterattack defence phase, the highest level of competition achieves a larger number of points that the lower level of competition (4\% to $8 \%$ ). The trend could be due to the higher occurrence of "out of system" attacks. In these situations, the blockers may balance their options against the spikers (Palao et al., 2004b) with a higher occurrence of slower passes (Castro et al., 2011; Silva et al., 2014). In the side-out phase, spikers have better conditions to finish the rally 
(Bergeles \& Nikolaidou, 2011; Inkinen et al., 2013; Palao et al., 2005). The counter-attack impacts the construction of the offence more often than the serve does; therefore, in this phase, the spike and the block have a greater balance (Bergeles et al., 2009; Kapidzic et al., 2013).

Related to the block intervention, in early stages, there are fewer contacts with the ball in blocking than at higher levels. In these categories, although the net height is lower, the players' jump capacity, technical skill, experience and decision making about the ball's trajectory are also lower (Amasay, 2008; Araujo et al., 2011; Inkinen et al., 2013; Malá et al., 2010). In a higher level of competition, there is a similar use of the block of two players and an increase in the errors and block that limits the opponent attacks (Marcelino \& Mequita, 2006). The disadvantage of the blockers compared to the opposite's spikers could cause these tendencies. There is a deficit in time from having to "read" the setter's movements in their passes, to watch the movements of the quicker attacks, and the conjunction with the partners in a collective block (Afonso \& Mesquita, 2011; Marcelino et al., 2014; Palao et al., 2005; Selinger \& Ackermann-Blount, 1985).

Regarding the blocking zone, a higher number of blocking actions in the lower categories were found in zone 3 in the counterattack phase. This could be due to teams attacking, in early stages, in the middle of the net using a second tempo attack. This type can be executed in all game conditions. At senior levels, the type of offence done in the middle of the net change, due to the improvement of the ball control, the realization of quick attacks by the middle hitters, and the usage of attacks from zone six (Palao \& Echeverría, 2008; Palao et al., 2005). At senior categories, the use of zone 3 is lower, although there are better conditions to build the offence (Costa, Afonso, Barbosa, Coutinho, \& Mesquita, 2014; Inkinen et al., 2013; João, Carvalho, Sattler \& Mota, 2007; João, Mesquita \& Sampaio, 2010). At senior categories, the zones most commonly used were the side of the net. The difficulty if making a good floor-defense against the higher level's spikers (Palao et al., 2005) may lead to playing the attacks at the wings side of the net with slower tempos (Costa et al., 2014; Palao et al., 2009), and thus makes a higher number of blocks in those zones.

Regarding the number of blockers, the under-18 and senior categories presented similar proportions: seven out of 10 blocks were done by two players, and two out of 10 blocks were done by one player. The blocks done by three players presented a low occurrence (1-3\%). These findings show that teams do not use a common strategy to neutralize the opponents' attack. At early stages, there was a higher occurrence of the blocks done by one player, and there were fewer blocks that touched the ball. At these categories, the development of abilities such as decision-making, anticipation or physical capacities are not completely developed (Afonso \& Mesquita, 2011; Amasay, 2008; Malá et al., 2010; Marcelino et al. 2014). Analysing this variable, it should take into account that the target of the block is not only to stop the attack but also to serve as a reference position to organize the second-line defence (Selinger \& Ackermann-Blount, 1985). At higher competition levels, there is a reduction of the time from the reception to the set and from the set to the attack (Inkinen et al., 2013; Katsikadelli, 1995). For that reason, although the physical capacity, training, and experience of the blockers increase, these improvements do not improve the block performance.

\section{Conclusions}

The data of this study provide reference values of the evolution of the occurrence, frequency of use, way of execution, and block efficacy from under-14 to elite female volleyball players. At higher categories, the participation of the block in the game increases. The efficacy of the block is similar in the different categories, due to the increase of the number of errors and the blocks that limits the opponent attack. The blockers participate more in the game when the attack is done in slower and less stable conditions (counter-attack). These data could help coaches to analyse and evaluate the block in their players and to develop training plans adapted to their requirements. An example of a practical application of the results of these studies could be the criteria of how many attack blocks should touch and get points for each age group and level of competition. For example, at the international level, the goal should be that the block contacts the ball with at least five out of 10 attacks, without allowing more than one block-out of 10 attacks. To properly apply the results, it should be taken into account that the data come from teams at a specific moment of their development and top-teams of each competition. Future longitudinal studies with large samples are necessary in order to confirm these results.

\section{References}

Afonso, J. \& Mesquita, I. (2011). Determinants of block cohesiveness and attack efficacy in high-level women's volleyball. European Journal of Sport Sciences, 11(1), 69-75. doi: 10.1080/17461391.2010.487114

Amasay, T. (2008). Statistic block jump techniques in volleyball: upright versus squat starting positions. The Journal of Strength and Conditioning Research, 22(4), 1242-1248. doi: 10.1519/JSC.0b013e31816d5a7f

Anguera, M. T., Blanco, A. \& Losada, J. L. (2001). Diseños observacionales, cuestión clave en el proceso de la metodología observacional [Observational design, key aspect in the process of the observational methodology]. Metodología de las Ciencias del Comportamiento, 3(2), 135-160.

Araújo, R., Afonso, J. \& Mesquita, I. (2011). Procedural knowledge, decisión-making and game performance analysis in female volleyball's attack according to the player's experience and competitive success. International Journal of Performance Analysis in Sport, 11(1), 1-13. doi: 10.1080/24748668.2011.11868524

Bergeles, N. \& Nikolaidou, M. E. (2011). Setter's performance and attack tempo as determinants of attack efficacy in Olympic-level male volleyball teams. International Journal of Performance Analysis in Sport, 
11(3), 535-544. doi: 10.1080/24748668.2011.11868571

Bergeles, N., Barzouca, K. \& Nikolaidou, M. E. (2009). Performance of female setters and attackers on olympic-level volleyball teams. International Journal of Performance Analysis of Sport, 9(1), 141-148. doi: $10.1080 / 24748668.2009 .11868470$

Castro, J., Souza, A. \& Mesquita, I. (2011). Attack efficacy in volleyball: elite male teams. Perceptual and Motor Skills, 113(2), 395-408. doi: 10.2466/05.25.PMS.113.5.395-408

Costa, G., Afonso, J., Barbosa, R. V., Coutinho, P. \& Mesquita, I. (2014). Predictors of attack efficacy and attack type in high-level Brazilian women's volleyball. Kinesiology, 46(2), 242-248.

Eom, H. J. \& Schutz, R. W. (1992a). Statistical analyses of volleyball team performance. Research Quarterly for Exercise and Sport, 63(1), 11-18. doi: 10.1080/02701367.1992.10607551

García-Alcaraz, A., Ortega, E., \& Palao, J. M. (2016). Technical-tactical performance profile of the block and dig according to competition category in men's volleyball. Motriz, 22(2), 102-109. doi: 10.1590/S19806574201600020013

Inkinen, V., Häyrinen, M. \& Linnamo, V. (2013). Technical and tactical analysis of women's volleyball. Biomedical Human Kinetics, 5, 43-50. doi: 10.2478/bhk-2013-0007

João, P. V., Carvalho, J, Sattler, T. \& Mota, M. P. (2007, July). Attack organization in-system and off-system by the setter, in volleyball team of Castelo Da Maia Ginásio. Paper presented at the XII Annual Congress of the ECSS, Jyväskylä, Finland. Retrieved May 18, 2018, from https://www.researchgate.net/publication/233819232_ Characterizing_the_efficacy_of_skills_in_high_performance_competitive_volleyball

João, P. V., Mesquita, I. \& Sampaio, J. (2010). Sex differences in discriminative power of volleyball gamerelated statistics. Perceptual and Motor Skill, 111(3), 893-900. doi: 10.2466/05.11.25.PMS.111.6.893-900

Kapidzic, A., Ahmic, D. \& Selimovic, N. (2013). Analysis of situational efficiency for winning and losing teams in 2010 volleyball world championship. Sport Science, 6(2), 82-92.

Katsikadelli, A. (1995). Tactical analysis of the attack serve in high-level volleyball. Journal of human movement studies, 29(5), 219-228.

Malá, L., Malý, T., Záhalka, F. \& Bunc, V. (2010). The profile and comparasion of body composition of elite female volleyball players. Kinesiology, 42(1), 90-97.

Marcelino, R. \& Mesquita, I. (2006, August). Characterizing the efficacy of skills in high-performance competitive volleyball. Paper presented at the VII World Conference of Performance Analysis of Sport, Szombathely, Hungría. Retrieved May 15, 2018, from https://www.researchgate.net/publication/233819232_ Characterizing_the_efficacy_of_skills_in_high_performance_competitive_volleyball

Marcelino, R., Afonso, J., Moraes, J. C. \& Mesquita, I. (2014). Determinants of attack players in high-level men's volleyball. Kinesiology, 46(2), 234-241.

McGown, C, Fronske, H. \& Moser, L. (2001). Coaching volleyball: building a winning team. Needham Heights: Allyn \& Bacon.

Palao, J. M. \& Echeverría, C. (2008). Evolución de la utilización colocación en salto en el voleibol femenino y su efecto sobre el juego [Evolution of the use of jump set in female volleyball and its effect on the game]. Kronos, 7(13), 35-44.

Palao, J. M. \& Manzanares, P. (2009). TEVOL: manual del instrumento de observación de las técnicas y la eficacia en voleibol (versión 1.0) [TEVOL: Manual for observation instrument of techniques and efficacy in volleyball (version 1.0)]. Retrieved May 10, 2018, from https://sites.google.com/site/tevolmanual/

Palao, J. M., Manzanares, P. \& Ortega, E. (2015). Design, validation, and reliability of an observation instrument for technical and tactical actions in indoor volleyball. European Journal of Human Movement, 34, 75-95.

Palao, J. M., Santos, J. A. \& Ureña, A. (2004a). Efecto del tipo y eficacia del saque sobre el bloqueo y el rendimiento del equipo en defensa [Effect of serve type and efficay on block and defense performance in volleyball]. RendimientoDeportivo.com, 8. Retrieved April 3, 2018, from https://www.researchgate.net/ publication/255994932_Efecto_del_tipo_y_eficacia_del_saque_sobre_el_bloqueo_y_el_rendimiento_del_ equipo_en_defensa_Effect_of_serve_type_and_efficay_on_block_and_defense_performance_in_volleyball

Palao, J. M., Santos, J. A. \& Ureña, A. (2004b). The effect of setter's position on the block in volleyball. The International Journal of Volleyball research, 6(1), 29-32.

Palao, J. M., Santos, J. A. \& Ureña, A. (2005). The effect of setter's position on the spike in volleyball. Journal of Human Movement Studies, 48(1), 25-40.

Peña, J., Rodríguez-Guerra, J., Buscá, B. \& Serra, N. (2013). Which skills and factors better predict winning and losing in high-level men's volleyball? Journal of Strength \& Conditioning Research, 27(9), 2487-2493. doi: 10.1519/JSC.0b013e31827f4dbe

Pereda, S. (1987). Psicología experimental [Experimental psychology]. Madrid: Pirámide.

Rodríguez-Ruiz, D., Quiroga, M., Mirralles, J. A., Sarmiento, S., de Saa, Y. \& García-Manso, J. M. (2011). Study of the technical and tactical variables determining set win or loss in top-level European men's volleyball. Journal of Quantitative Analysis in Sports, 7(1), 1-15. doi: 10.2202/1559-0410.1281

Selinger, A. \& Ackermann-Blount, J. (1985). Arie Selinger's power volleyball. New York: St. Martin Press.

Silva, M., Lacerda, D. \& João, P. V. (2014). Match analysis of discrimination skills according to the setter defence zone position in high level volleyball. International Journal of Performance Analysis in Sport, 14(2), 463-472. doi: 10.1080/24748668.2014.11868735

Vint, P.F. (1998). Hitting biomechanics: the foundation of skill application. Coaching volleyball, April/May, $10-15$. 